Bayesian estimation of test characteristics of real-time PCR, bacteriological culture and California mastitis test for diagnosis of intramammary infections with Staphylococcus aureus in dairy cattle at routine milk recordings

Mahmmod, Yasser; Toft, Nils; Katholm, Jørgen; Grønbæk, Carsten; Klaas, Ilka Christine

Published in:

Preventive Veterinary Medicine

DOI:

10.1016/j.prevetmed.2013.07.021

Publication date:

2013

Document version

Early version, also known as pre-print

Citation for published version (APA):

Mahmmod, Y., Toft, N., Katholm, J., Grønbæk, C., \& Klaas, I. C. (2013). Bayesian estimation of test characteristics of real-time PCR, bacteriological culture and California mastitis test for diagnosis of intramammary infections with Staphylococcus aureus in dairy cattle at routine milk recordings. Preventive Veterinary Medicine, 112(3-4), 309-317. https://doi.org/10.1016/j.prevetmed.2013.07.021 


\title{
Bayesian estimation of test characteristics of real-time PCR, bacteriological culture and California mastitis test for diagnosis of intramammary infections with Staphylococcus aureus in dairy cattle at routine milk recordings
}

\author{
Yasser S. Mahmmod a,b,*, Nils Toft ${ }^{\mathrm{c}}$, Jørgen Katholm ${ }^{\mathrm{d}}$, \\ Carsten Grønbæk ${ }^{\mathrm{e}}$, Ilka C. Klaas ${ }^{\mathrm{a}}$ \\ ${ }^{a}$ HERD: Centre for Herd-oriented Education, Research and Development, Department of Large Animal Sciences, Faculty of Health and \\ Medical Sciences, University of Copenhagen, DK-1870 Frederiksberg C, Copenhagen, Denmark \\ b Infectious Diseases, Department of Animal Medicine, Faculty of Veterinary Medicine, Zagazig University, Zagazig City 44511, Sharkia \\ Province, Egypt \\ c Department of Large Animal Sciences, Faculty of Health and Medical Sciences, University of Copenhagen, DK-1870 Frederiksberg C, \\ Copenhagen, Denmark \\ d Knowledge Centre for Agriculture, Cattle, Agro Food Park 15, Skejby, DK-8200 Aarhus N, Denmark \\ e Eurofins Steins Laboratory, DK-7500 Holstebro, Denmark
}

\section{A R T I C L E I N F O}

\section{Article history:}

Received 11 December 2012

Received in revised form 30 July 2013

Accepted 31 July 2013

\section{Keywords:}

Staphylococcus aureus

PathoProof ${ }^{\mathrm{TM}}$ Mastitis PCR assay

Conventional diagnostics

Sensitivity and Specificity

Test misclassification

Dairy cows

\begin{abstract}
A B S T R A C T
Danish farmers can order a real-time PCR mastitis diagnostic test on routinely taken cow-level samples from milk recordings. Validation of its performance in comparison to conventional mastitis diagnostics under field conditions is essential for efficient control of intramammary infections (IMI) with Staphylococcus aureus (S. aureus). Therefore, the objective of this study was to estimate the sensitivity (Se) and specificity (Sp) of real-time PCR, bacterial culture (BC) and California mastitis test (CMT) for the diagnosis of the naturally occurring IMI with $S$. aureus in routinely collected milk samples using latent class analysis (LCA) to avoid the assumption of a perfect reference test. Using systematic random sampling, a total of 609 lactating dairy cows were selected from 6 dairy herds with bulk tank milk PCR cycle threshold (Ct) value $\leq 39$ for $S$. aureus. At routine milk recordings, automatically obtained cow-level (composite) milk samples were analyzed by PCR and at the same milking, 2436 quarter milk samples were collected aseptically for BC and CMT. Results showed that 140 cows (23\%) were positive for S. aureus IMI by BC while 170 cows (28\%) were positive by PCR. Estimates of Se and Sp for PCR were higher than test estimates of BC and CMT. $\mathrm{Se}_{\mathrm{CMT}}$ was higher than $\mathrm{Se}_{\mathrm{BC}}$ however, $\mathrm{Sp}_{\mathrm{BC}}$ was higher than $\mathrm{Sp}_{\mathrm{CMT}}$. $S \mathrm{~S}_{\mathrm{PCR}}$ was $91 \%$, while $\mathrm{Se}_{\mathrm{BC}}$ was $53 \%$, and $\mathrm{Se}_{\mathrm{CMT}}$ was $61 \%$. $\mathrm{Sp}_{\mathrm{PCR}}$ was $99 \%$, while $\mathrm{Sp} \mathrm{p}_{\mathrm{BC}}$ was $89 \%$, and $\mathrm{Sp}_{\mathrm{CMT}}$ was $65 \%$.

In conclusion, PCR has a higher performance than the conventional diagnostic tests (BC and CMT) suggesting its usefulness as a routine test for accurate diagnosis of $S$. aureus IMI from dairy cows at routine milk recordings. The use of LCA provided estimates of the test characteristics for two currently diagnostic tests (BC, CMT) and a novel technique (realtime PCR) for diagnosing $S$. aureus IMI under field conditions at routine milk recordings in Denmark.
\end{abstract}

(c) 2013 Elsevier B.V. All rights reserved.

\footnotetext{
* Corresponding author at: HERD: Centre for Herd-oriented Education, Research and Development, Department of Large Animal Sciences, Faculty of Health and Medical Sciences, University of Copenhagen, DK-1870 Frederiksberg C, Copenhagen, Denmark. Tel.: +45 35333056 ; fax: +45 35 33 30 22.

E-mail addresses: yasser@sund.ku.dk, yasser_saad_eldien@yahoo.com (Y.S. Mahmmod).
}

0167-5877/\$ - see front matter @ 2013 Elsevier B.V. All rights reserved.

http://dx.doi.org/10.1016/j.prevetmed.2013.07.021 


\section{Introduction}

Staphylococcus aureus (S. aureus) is a major cause of intramammary infections (IMI) leading to damage of udder tissue and clinical mastitis episodes with subsequent high economic losses (Barkema et al., 2006; Reyher et al., 2012). Halasa et al. (2009) concluded that subclinical IMI with $S$. aureus was associated with high economic losses of an average of $€ 1219$ total annual net costs for a herd of 100 dairy cows. Sørensen et al. (2010) reported that clinical S. aureus IMI was associated with the highest economic losses of $€ 570$ per case, in comparison to economic losses caused by other investigated mastitis pathogens. Hence, reducing the incidence of S. aureus IMI in dairy cows represents a corner stone for economically sound udder health management. However, the reduction of the incidence of $S$. aureus IMI will definitely require an accurate diagnostic test. Therefore, diagnostic techniques with high performance are a necessity for efficient biosecurity and control of S. aureus IMI.

The control of S. aureus is contingent on accurate diagnosis of IMI, and bacteriological culture (BC) of milk samples is the most common carried out diagnostics of $S$. aureus IMI. The sensitivity (Se) of BC for detection of S. aureus IMI from single quarter milk samples has previously been estimated to $75 \%$ (Sears et al., 1990), to 62\% (Sanford et al., 2006), and a range 44-90\% based on 12 different definitions of IMI (Dohoo et al., 2011). The Se can be increased to 94-99\%, if two or three consecutive samples are collected over a period of time (Sears et al., 1990; Buelow et al., 1996; Anderson and Pritchard, 2012), however, such requirements are cumbersome and cost prohibitive in field studies and day-to-day mastitis diagnostics. S. aureus bacteria are shedded intermittently (Sears et al., 1990; Anderson and Pritchard, 2012), so that the numbers of $S$. aureus bacterial numbers in milk may be high for a while, followed by a period with much lower to undetectable numbers. As a consequence not all the bacterial cells of $S$. aureus that are present in an infected mammary gland will be present in single milk sample (Sol et al., 2002; Ghorbanpoor et al., 2007). Hence, BC may not be completely satisfactory for the diagnosis of $S$. aureus IMI.

The California mastitis test (CMT) has been accepted as a quick, cheap, and simple cow-side test for screening for subclinical IMI under field conditions (Schalm and Noorlander, 1957). Sanford et al. (2006) found that the Se and Sp of CMT for identifying the major pathogens including S. aureus were $79 \%$ and $46 \%$, respectively, while they were $66.7 \%$ and $54.8 \%$, respectively in a study by Sargeant et al. (2001). The CMT can be used to point out potentially subclinically infected cows for follow-up diagnostics with BC or PCR.

A commercially available multiplex real-time PCR technique such as the PathoProof ${ }^{\mathrm{TM}}$ Mastitis PCR Assay (Thermo Fisher Scientific, Vantaa, Finland), is a faster and accurate alternative to BC (Taponen et al., 2009; Koskinen et al., 2009). The assay has previously shown a higher Se and specificity ( $\mathrm{Sp}$ ) than $\mathrm{BC}$ in isolates originating from clinical bovine mastitis (Koskinen et al., 2009) and subclinical IMI with Streptococcus agalactiae (S. agalactiae) (Mahmmod et al., 2013a). The assay is performed directly on raw or preserved milk samples and takes about 3-4h from DNA extraction until results are available.

Since 2010, Danish farmers have been able to order cow-level PCR tests (PathoProof ${ }^{\mathrm{TM}}$ Mastitis PCR assay) automatically as part of routine milk testing (Katholm, 2010). Relatively few published studies have evaluated the accuracy of different PCR techniques based on comparison to imperfect reference tests (Ahmadi et al., 2010; Friendship et al., 2010). On quarter-level, Paradis et al. (2012) estimated the diagnostic accuracy of a multiplex real-time PCR and BC for subclinical IMI with S. aureus using Bayesian analysis. The authors estimated the Se of BC of $66 \%$ and $83 \%$ based on the IMI definition of $10 \mathrm{cfu}$ and $1 \mathrm{cfu}$ per $0.01 \mathrm{ml}$, while the Se of PCR was $95 \%$ and $88 \%$, respectively. In both tests Sp was $\geq 99 \%$. Cederlöf et al. (2012) reported Se and Sp of 93\% and 95\% for PCR tests on routinely taken samples from milk recording, while it was $83 \%$ and $97 \%$ for BC on sterile quarter foremilk samples, respectively. In that study, all milk samples used for BC were frozen prior to analysis. Freezing was found to increase the likelihood for obtaining $S$. aureus in the milk sample and improve the Se of BC (Villanueva et al., 1991; Sol et al., 2002). To the best of our knowledge, PCR tests have not been evaluated on cow level against BC and CMT from fresh milk samples obtained as part of routine milk recording from all cows within the herd.

When neither diagnostic test can be regarded as perfect test, latent class analysis (LCA) (Hui and Walter, 1980) can be an alternative procedure, which does not assume that the accuracy of either the reference test or the test under evaluation is known (or that a perfect reference test for subject classification is available). By using LCA, the disease status exists but is not known; it is latent (Toft et al., 2007). Using LCA Sanford et al. (2006) estimated the Se and Sp of CMT and BC for detection of IMI at dry-off and demonstrated that CMT could be a valuable tool to identify cows with IMI for selective dry cow treatments in herds with low prevalence of major pathogens. However, studies estimating the Se and Sp of PCR from routinely collected test-day samples against CMT and BC for S. aureus from randomly selected cows in different stages of lactation have not yet been published. The objective of this study was to estimate the Se and Sp of real-time PCR assay, BC and CMT for the diagnosis of the naturally occurring IMI with $S$. aureus in routinely collected milk samples using LCA to avoid the assumption of a perfect reference test.

\section{Materials and methods}

\subsection{Study population}

Six dairy herds with Danish Holstein cows were selected from 34 Danish dairy herds participating in a project investigating relations between bulk tank PCR and the prevalence of $S$. agalactiae and $S$. aureus in the herds (Mahmmod et al., 2013a). To be eligible for inclusion in the present study, herds had to have a conventional milking parlour and a bulk tank milk (BTM) PCR Ct value $\leq 39$ for $S$. agalactiae and $S$. aureus at the annual PCR testing in October 2010. The cut-off was chosen according to Katholm et al. (2012), as it is a common practice for bulk tank 
monitoring of mastitis pathogens in Denmark. Seven herds met the criteria. Furthermore, monthly PCR BTM tests were taken from January to March 2011. One herd had a Ct value of 40 for $S$. agalactiae in each test and was excluded, while the remaining six herds had $\mathrm{Ct}$ values of $\leq 37$ in at least two out of three tests. We regard these six herds as representative for herds with loose-housing systems and conventional milking parlour.

\subsection{Cow selection}

For collection of cow-level (composite) milk samples for PCR testing, all lactating dairy cows within the herds were sampled. For collection of quarter milk samples for $\mathrm{BC}$, approximately $50 \%$ of the lactating dairy cows in each herd were selected using systematic random sampling for the milking unit (milking place) as follows; in herringbone or side-by-side parlours, all cows milked at the first, the third, and the fifth unit on the one side and the second, the forth, and the sixth on the other side were sampled. In the herd with a rotary parlour all cows at every second milking unit were sampled.

\subsection{Sample collection}

Between 28th March and 28th May 2011 each herd was visited by two trained technicians from the Knowledge Centre for Agriculture, Cattle (Aarhus, Denmark) at the milking of the routine milk recording. After the farm personnel had carried out their routine pre-milking practices, quarter milk samples were collected aseptically before attachment of the milking device from the randomly selected cows following the procedure according to the National Mastitis Council recommendations (NMC, 1999). About $5 \mathrm{ml}$ milk was collected aseptically from each quarter of each cow in clean sterile snap-cap plastic tubes, which were placed in ice boxes at $5^{\circ} \mathrm{C}$. Ice boxes were delivered to the Eurofins Steins Laboratory (Holstebro, Denmark) within $12 \mathrm{~h}$ of collection for BC and CMT.

At the same milking when quarter foremilk samples were taken, Bronopol preserved composite milk samples were automatically taken with the Tru-test Electronic Milk Metre device (Tru-Test Group Company, New Zealand) as part of the ordinary DHI sampling. Samples were delivered to Eurofins Steins Laboratory within $24 \mathrm{~h}$ for PCR analysis.

\subsection{Real-time PCR testing}

The collected cow-level milk samples were tested using the PathoProof ${ }^{\mathrm{TM}}$ Mastitis PCR assay (Thermo Fisher Scientific, Vantaa, Finland). The PCR testing was performed at the section of Microbiology at Eurofins Steins Laboratory according to the instructions of the manufacturer. A total of $350 \mu \mathrm{l}$ of milk was used as a starting volume for the DNA extraction. The DNA extraction protocol involved an enzymatic lysis step, disrupting the cell walls of gram-positive and gram-negative bacteria, as well as spin column-based DNA purification and elution steps (see Koskinen et al., 2009, for further details). Ct values were recorded for all samples, targeting DNA of $S$. aureus. The $\mathrm{Ct}$ value represents the number of PCR cycles required to reach a set threshold fluorescence signal level (Koskinen et al., 2009). It is used as a measurement of the load of bacterial DNA in the tested sample. The thermal cycling protocol for the PCR assay involved 40 cycles for the reaction. The higher the numbers of bacteria DNA present in the milk sample, the lower the Ct value obtained with the assay (Koskinen et al., 2008). Lower Ct values are indicative for higher DNA concentrations of $S$. aureus in the milk sample.

\subsection{Bacteriological culturing and CMT}

BC was performed by the first author according to the guidelines of the National Mastitis Council (NMC, 1999) by aseptically spreading $0.01 \mathrm{ml}$ of each milk sample from each quarter on a calf blood agar plate and $0.01 \mathrm{ml}$ of the same sample on Chrome agar media with a disposable, calibrated bacterial loop. Inoculated plates were marked by the cow identity and the sequence of the quarters, and then incubated aerobically at $37^{\circ} \mathrm{C}$. After 24 and $48 \mathrm{~h}$ the plates were read for the growth of $S$. aureus colonies. Samples were considered negative if no growth occurred after $48 \mathrm{~h}$. On blood agar, $S$. aureus was identified by the appearance of greyish-white to yellow-orange colonies with double zones of hemolysis (NMC, 2004). On chrome agar, S. aureus colonies were identified by its characteristic golden yellow colour. In suspicious cases, confirmatory tests for definite diagnosis were performed such as $\mathrm{KOH}$ test, catalase test, and coagulase test.

At Eurofins lab, CMT was performed by the first author as described by Schalm and Noorlander (1957) for each collected quarter milk sample. The test scored on a five point scale with score one as completely negative, score three as clearly positive and score five as a maximum (Bennedsgaard et al., 2006). The laboratory personnel were blinded concerning the cow identity, BC- and PCR-results when scoring the CMT.

\subsection{Test categorization}

Positivity for S. aureus IMI on BC was defined in the following cases; (1) identification of greater than or equal to two colonies of $S$. aureus on pure or mixed blood agar plate from an individual quarter milk sample (Buelow et al., 1996), or (2) if the quarter was defined as contaminated and S. aureus was part of such contamination, the quarter was considered as positive for $S$. aureus (Dohoo et al., 2011). If a cow had at least one quarter positive for $S$. aureus, the cow was considered test positive by BC. If a cow had at one quarter positive for $S$. aureus and another quarter regarded as contaminated, the cow was considered test positive by BC. Quarter milk samples, from which 3 or more species of colonies were isolated, were regarded as contaminated (NMC, 1999).

For CMT, an individual mammary quarter milk sample was defined as positive if CMT score $\geq 3$. If a cow had at least one positive quarter, the cow was considered test positive by CMT. Regarding the PathoProof ${ }^{\mathrm{TM}}$ Mastitis PCR Assay (Thermo Fisher Scientific, Vantaa, Finland); the thermal cycling protocol involved 40 cycles for the reaction. We 
used the recommended cut-off with Ct values $\leq 37$ defined as positive (Bexiga et al., 2011).

\subsection{Statistical analysis}

In the absence of a reference standard test to identify the true S. aureus IMI status of a cow, the test characteristics of PCR, CMT and BC results were analyzed using a modified version of the LCA introduced by Hui and Walter (1980). In this study we used a Bayesian model, which is essentially the same as the one used in Toft et al. (2007) and we refer to this study for further description. It was assumed a priori that the prevalence of $S$. aureus in the samples from the 6 herds would differ and that the test characteristics could be considered constant across the herds. The BC and CMT were not considered conditionally independent (CID) given disease status, due to them being carried out on the same quarter milk samples. Therefore, a model was used, which allowed for conditional covariance between the two tests, while assuming CID between PCR and both $\mathrm{CMT}$ and $\mathrm{BC}$. To verify the importance of the assumption of conditional covariance, the model was compared to a model assuming CID between all tests, as well as models assuming conditional dependence between the other pairs of tests, i.e. BC and PCR or CMT and PCR. Model comparison was done by comparing Deviance Information Criteria (DIC) (Spiegelhalter et al., 2002) and by judging if changes in posterior estimates changed the biological conclusions about the test and the implied latent disease (IMI) definition. Furthermore, to check if the CMT had influence on the estimates for BC and PCR, a model without CMT assuming CID between PCR and BC was run.

In a Bayesian analysis, all parameters are modelled using distributions, where prior distributions are provided to reflect what is known about the model parameters independently of the study results. However, there is no published evidence of the diagnostic properties for the tests under comparison, when applied to naturally occurring (subclinical) infections from routine milking recordings based on latent class approach. Thus, we chose to use uninformative priors in the shape of uniform distributions on the interval between zero and one, modelled using the Beta $(1,1)$ distribution. The priors for the covariance were modelled using uniform distributions with ranges given by the limits described in Toft et al. (2007). The model was implemented in OpenBUGS software, version 3.2.2 rev 781 (Thomas et al., 2006), which uses a Markov Chain Monte Carlo (MCMC) sampling algorithm to obtain a Monte Carlo (MC) sample from the joint posterior distribution of all model parameters. The MCMC chain was run for 20,000 iterations of the model and the first 10,000 were discarded as the burn-in phase. Convergence of the MCMC chain after the initial burn-in was assessed by visual inspection of the time-series plots of selected variables as well as Gelman-Rubin diagnostic plots using three sample chains with different initial values (Gelman and Rubin, 1992). The posterior distribution of the population prevalence, the Se and $\mathrm{Sp}$ of the three tests, and the conditional covariance were reported as the median and corresponding $95 \%$ posterior credibility interval $(\mathrm{PCI})$.

\section{Results}

A total of 624 cows were selected by systematic random sampling within the 6 herds for BC, CMT and PCR testing. Due to missing values in PCR testing, 15 cows were excluded from the analysis. A total of 40 cows had at least one quarter regarded as contaminated. Out of these 40 cows, 25 cows with 26 contaminated quarters, where S. aureus was not part of the contamination, were negative in both BC (for all other quarters) and PCR. Twelve cows out of 15 with $S$. aureus contaminated quarters had at least one other quarter infected with $S$. aureus based on BC as well as PCR. The remaining three other cows with $S$. aureus contaminated quarters had no S. aureus infection. The analysis was performed for two datasets, with and without excluding the 25 cows with contamination, where $S$. aureus was not part of this contamination. The results showed no significant difference between the obtained estimates for the two datasets and therefore, we present the results for the dataset with excluding the 25 cows (609 cows) to include the information from all quarters.

In each of the six herds, the test outcomes of the test 1 (BC of $S$. aureus), test 2 (CMT $\geq 3$ at least 1 quarter), and test 3 (PCR Ct value $\leq 37$ ) from the 609 cows (2436 quarter milk samples) were cross classified into $2 \times 2$ tables, Table 1. Based on these tabulated data for the 6 herds, Se and Sp for PCR, BC and CMT, the conditional covariance parameters (Cov.Se and Cov.Sp) between BC and CMT, as well as the prevalence of $S$. aureus IMI in each herd was estimated (Tables 2 and 3). The prevalence of S. aureus IMI based on BC was $23 \%$ (140/609), while it was $28 \%$ (170/609) based on PCR. The median posterior Se and Sp estimates of PCR were higher than those for BC and CMT. CMT was more sensitive than $B C$, but lacked specificity compared to $\mathrm{BC}$. Based on the DIC, the model assuming conditional covariance (COC) between $\mathrm{BC}$ and CMT was preferred over other COC combination models scenarios and CID model (DIC $=252.5$, compared to DIC $=270.0$ for a model assuming CID, DIC $=264.3$ for a model assuming COC between PCR and BC, and DIC $=264.7$ for a model assuming COC between PCR and CMT). In the model Cov.Se was significant, i.e. the $95 \% \mathrm{PCI}$ did not cover 0 , while $\mathrm{Cov}$, Sp was not. To check if the CMT influenced the test estimates for BC and PCR, a model without CMT assuming CID between PCR and $\mathrm{BC}$ showed that CMT did not affect the findings and overall conclusions substantially, indicating that the latent disease definition is indeed driven by presence of $S$. aureus, Table 4.

\section{Discussion}

This is the first reported study of an LCA estimating the Se and Sp of PCR, CMT and BC at cow-level without the assumption of a reference standard for detection of S. aureus in freshly collected milk samples of dairy cows under field conditions, at routine milk recordings. The performance of PCR was better with respect to both Se and Sp compared to BC and CMT. 
Table 1

Cross-tabulated results for bacterial culture (BC), test 1 ( 1 , bacterial culture (BC) of Staphylococcus aureus), test 2 (T2, California mastitis test (CMT) $\geq 3$ in at least 1 quarter), and test 3 (T3, PCR Ct-value cut-off $\leq 37$ ) used for diagnosis of intramammary infection with Staphylococcus aureus in six dairy herds.

\begin{tabular}{|c|c|c|c|c|c|c|c|c|c|}
\hline \multirow[t]{2}{*}{ Herd } & \multicolumn{8}{|c|}{ Tests combination (BC T1, CMT T2, PCR T3) } & \multirow[t]{2}{*}{ Total $(n)$} \\
\hline & +++ & ++- & +-+ & +-- & -++ & -+- & --+ & --- & \\
\hline H1 & 5 & 2 & 2 & 4 & 0 & 15 & 0 & 38 & 66 \\
\hline $\mathrm{H} 2$ & 11 & 9 & 7 & 14 & 0 & 28 & 7 & 96 & 172 \\
\hline H3 & 5 & 4 & 1 & 1 & 8 & 29 & 7 & 20 & 75 \\
\hline $\mathrm{H} 4$ & 10 & 5 & 0 & 0 & 8 & 29 & 10 & 34 & 96 \\
\hline H5 & 21 & 2 & 5 & 8 & 11 & 18 & 20 & 38 & 123 \\
\hline H6 & 15 & 2 & 6 & 1 & 7 & 16 & 4 & 26 & 77 \\
\hline
\end{tabular}

Table 2

Latent class estimates (posterior median and $95 \%$ posterior credibility interval ( $\mathrm{PCI})$ ) of test sensitivity (Se), $\mathrm{specificity}(\mathrm{Sp})$ for bacterial culture (Se $\mathrm{BC}_{\mathrm{BC}}, \mathrm{Sp} \mathrm{B}_{\mathrm{BC}}$ ), CMT ( $\mathrm{Se}_{\mathrm{CMT}}, \mathrm{Sp}_{\mathrm{CMT}}$ ) and real-time PCR assay (Se $\mathrm{PCR}_{\text {, S PCR }}$ ) used for diagnosis of intramammary infections with Staphylococcus aureus at cut-offs for PCR Cycle threshold $(\mathrm{Ct})$ values $\leq 37$, with conditional covariance (Cov.Se and Cov.Sp) between BC and CMT.

\begin{tabular}{|c|c|c|c|c|c|c|c|c|c|}
\hline \multirow[t]{2}{*}{ PCR $^{\mathrm{a}}$ cut-off } & \multirow[t]{2}{*}{ Parameter } & \multicolumn{8}{|c|}{ Test estimates } \\
\hline & & $\mathrm{Se}_{\mathrm{BC}}$ & $\mathrm{Se}_{\mathrm{CMT}}$ & $\mathrm{Se}_{\mathrm{PCR}}$ & $\mathrm{Sp}_{\mathrm{BC}}$ & $\mathrm{Sp}_{\mathrm{CMT}}$ & $\mathrm{Sp}_{\mathrm{PCR}}$ & Cov.Se & Cov.Sp \\
\hline \multirow[t]{2}{*}{ Cut-off $\leq 37$} & Median (\%) & 52.8 & 60.6 & 91.2 & 89.4 & 64.7 & 98.6 & 0.081 & 0.006 \\
\hline & $95 \% \mathrm{PCI}$ & $44.7-61.7$ & $52.7-68.8$ & $74.5-99.5$ & 85.6-93.4 & $59.9-69.7$ & $93.7-100.0$ & $0.045-0.116$ & -0.012 to 0.024 \\
\hline
\end{tabular}

a $\mathrm{PCR}=$ PathoProof ${ }^{\mathrm{TM}}$ Mastitis PCR Assay (Thermo Fisher Scientific, Vantaa, Finland).

Table 3

Posterior median and 95\% posterior credibility interval (PCI)) of true prevalence of intramammary infections with Staphylococcus aureus in 6 Danish dairy herds tested with BC, CMT and PCR (PathoProof ${ }^{\mathrm{TM}}$ Mastitis PCR Assay (Thermo Fisher Scientific, Vantaa, Finland)).

\begin{tabular}{llllllll}
\hline \multirow{2}{*}{ PCR cut-off } & Parameter & \multicolumn{2}{l}{ True prevalence } & & \\
\cline { 3 - 6 } & & H1 & H2 & H3 & H4 & H6 \\
\hline \multirow{2}{*}{ Cut-off $\leq 37$} & Median (\%) & 12.2 & 15.6 & 29.8 & 30.9 & 49.2 \\
& $95 \%$ PCI & $5.3-22.7$ & $9.4-23.9$ & $17.7-44.2$ & $20.2-43.7$ & $38.2-61.5$ & $32.1-58.3$ \\
\hline
\end{tabular}

\section{Table 4}

Latent class estimates (posterior median and 95\% posterior credibility interval (PCI)) of test sensitivity (Se), specificity (Sp) for bacterial culture (Se $\mathrm{BC}_{\mathrm{BC}} \mathrm{Sp} \mathrm{p}_{\mathrm{BC}}$ ), and real-time PCR assay ( $\mathrm{Se}_{\mathrm{PCR}}$, $\mathrm{SP}_{\mathrm{PCR}}$ ) used for diagnosis of intramammary infections with Staphylococcus aureus at cut-offs for PCR Cycle threshold (Ct) values $\leq 37$, with unconditional dependence (CID) models.

\begin{tabular}{|c|c|c|c|c|c|}
\hline \multirow[t]{2}{*}{ PCR $^{\mathrm{a}}$ cut-off } & \multirow[t]{2}{*}{ Parameter } & \multicolumn{4}{|c|}{ Test estimates } \\
\hline & & $\mathrm{Se}_{\mathrm{BC}}$ & $\mathrm{Se}_{\mathrm{PCR}}$ & $\mathrm{Sp}_{\mathrm{BC}}$ & $\mathrm{Sp}_{\mathrm{PCR}}$ \\
\hline \multirow[t]{2}{*}{ Cut-off $\leq 37$} & Median (\%) & 52.3 & 90.8 & 89.5 & 98.8 \\
\hline & $95 \% \mathrm{PCI}$ & $44.2-61.1$ & 73.9-99.6 & $85.8-93.6$ & $94.2-100.0$ \\
\hline
\end{tabular}

${ }^{\text {a }}$ PCR $=$ PathoProof ${ }^{\mathrm{TM}}$ Mastitis PCR Assay (Thermo Fisher Scientific, Vantaa, Finland).

\subsection{Latent infection definition}

An implicit assumption of LCA model is that the three tests are measuring the same latent condition. In our case, this condition is the presence of $S$. aureus DNA in the milk, which we interpret as IMI with $S$. aureus. A positive PCR result indicates the presence of $S$. aureus DNA (Koskinen et al., 2009) without discriminating between viable and non-viable cells. A positive $B C$ result of an aseptically obtained milk sample indicates the presence of viable bacterial cells of $S$. aureus and hereby presumably invasion and multiplication of $S$. aureus in the mammary gland. A positive CMT result of an aseptically collected milk sample indicates a high cellular milk content/SCC, which is considered as a general indicator for subclinical intramammary infections; i.e. high numbers of bacteria induce high inflammatory response leading to high cellular contents of milk which is identified as positive CMT reaction. This inflammation is not exclusively caused by $S$. aureus and could be due to other mastitis pathogens or mixed infections or contaminations. However, Kivaria et al. (2007) concluded that there is a high association between CMT and BC for identification of $S$. aureus IMI. SCC, which can be identified by CMT, is a valuable component of monitoring programmes. Schukken et al. (2003) concluded that quarter and cow SCC directly represent the inflammatory status of the mammary gland and can measure the inflammatory response to an IMI. Recently, Koop et al. (2011) confirmed that composite SCC can be used as a screening tool to detect $S$. aureus-infected animals, but that a confirmatory test is needed to identify false-positive results.

\subsection{Test estimates variations}

The posterior median estimates of $\mathrm{Se}_{\mathrm{PCR}}$ and $\mathrm{SP}_{\mathrm{PCR}}$ were much higher than $\mathrm{Se}_{\mathrm{BC}}$ and $\mathrm{Sp}_{\mathrm{BC}}$, respectively. This reflects the ability of the PCR assay to detect DNA of $S$. aureus in milk samples as either viable, non-viable or growth-inhibited cells (Taponen et al., 2009; Koskinen et al., 2009), while BC allows the detection of only viable bacterial cells of $S$. 
aureus. This explanation may reveal why PCR has higher Se than BC. However, it would be expected to contribute to a lower Sp. The CMT acts by the unspecific reaction with the cellular and inflammatory DNA (bacterial cells + somatic cells) in milk samples (Dohoo and Meek, 1982).

Our findings for $\mathrm{Se}_{\mathrm{PCR}}$ and $\mathrm{Sp}_{\mathrm{PCR}}$ fall within the range of those reported previously by Cederlöf et al. (2012) [Se $=93 \%$ and $\mathrm{Sp}=95 \%$, Friendship et al. (2010) [ $\mathrm{Se}=94 \%$ and $\mathrm{SP}=95 \%$, and Koskinen (2012) [Se $=91.4 \%$ and $\mathrm{Sp}=95.6 \%$ ]. Our findings for $\mathrm{Se}_{\mathrm{BC}}$ and $\mathrm{Sp}_{\mathrm{BC}}$ were similar to those estimates reported by Buelow and Nordlund (1999) who found that $\mathrm{Se}_{\mathrm{BC}}$ for $\mathrm{S}$. aureus ranged from $54 \%$ to $92 \%$, while $\mathrm{Sp}_{\mathrm{BC}}$ ranged from $86 \%$ to $99.8 \%$. Sanford et al. (2006) estimated the $\mathrm{Se}_{\mathrm{BC}}$ and $\mathrm{Sp}_{\mathrm{BC}}$ for major mastitis pathogens (including S. aureus) to be $56 \%$ and $93 \%$. In contrast, our estimates for $\mathrm{BC}$ are different from those estimates reported by Dohoo et al. (2011) for IMI definition B ( $\geq 2$ with mixed growth), where the estimates were $\mathrm{Se}_{\mathrm{BC}}=90.4 \%$ and $\mathrm{Sp}_{\mathrm{BC}}=99.8 \%$ for S. aureus. Cederlöf et al. (2012) found that the estimates for $\mathrm{BC}$ were $(\mathrm{Se}=83 \%$ and $\mathrm{Sp}=97 \%$ ), which are higher than our obtained estimates. The possible reasons for this difference could be (a) they considered greater than or equal to one colony as a definition for S. aureus IMI on blood agar while we considered greater than or equal to two colonies, (b) their study population was cows at drying off while ours was all lactating dairy cows regardless the stage of lactation, and (c) prior to their BC, milk samples were frozen (improves Se), while in our study milk samples were freshly collected or chilled, not frozen, (d) for PCR, cows may have been selected by the farmers based on having higher SCC, and (e) their milk samples for BC were collected within $24 \mathrm{~h}$ after PCR sampling, while in our study, milk samples were collected at the same milking for both tests.

The low estimate for $\mathrm{Se}_{\mathrm{BC}}$ may be argued by the intermittent shedding of $S$. aureus from infected quarters during lactation (Sears et al., 1990), which may require several consecutive samples to isolate viable $S$. aureus necessary for an accurate diagnosis of the infected quarters (Buelow et al., 1996). Furthermore, viable S. aureus may be shed in too low amounts from truly subclinically infected glands to be present in the inoculum sample (Buelow et al., 1996; Cai et al., 2003). No doubt that the choice of one colony as a definition for IMI with S. aureus, will favourably improve the Se estimates as shown by Dohoo et al. (2011) and Cederlöf et al. (2012). The choice of two colonies as a definition for IMI could affect $\mathrm{Se}_{\mathrm{BC}}$ since quarters with one colony are considered as negative. However, the definition of IMI with S. aureus may not be the only factor that influences the test estimates, other factors such as procedures of sample collection, processing of milk samples, culturing procedures, definition of contamination, strains difference of S. aureus and their shedding pattern (Walker et al., 2011) may also be relevant. Sol et al. (2002) suggested that the $\mathrm{Se}_{\mathrm{BC}}$ was not affected only by the used culture technique but also by the moment of sampling, selection of the cows to be sampled, and incubation of milk samples. Quarter foremilk samples were collected for culture examination which may have a higher concentration of $S$. aureus in comparison to samples taken after milking (Sears et al., 1991). Kelton and Godkin (2000) added that $\mathrm{Se}_{\mathrm{BC}}$ and $\mathrm{Sp}_{\mathrm{BC}}$ may be influenced by other factors such as duration of infections, sample type (quarter, cow composite or bulk tank), the condition of the sample (fresh or frozen), the shedding pattern, the volume of milk plated (inoculum) and the frequency of sampling.

The low estimate of $\mathrm{Sp}_{\mathrm{BC}}$ could be argued by (1) contamination of milk samples at some point during sample collection in the farm and/or processing of milk samples in the laboratory; (2) a higher risk of contamination would be expected when collecting four individual quarters milk samples (by hand) for BC than when collecting one preserved composite milk sample (by metre) for PCR; (3) contamination of the bacterial agar plates used for isolation and identification of S. aureus. NMC (1999) reported the common sources of contamination including dirty teat ends, milk touch hands or fingers before entering the tube, non-sterile tubes, streaking milk samples on contaminated media; (4) high number of $S$. aureus bacteria colonizing teat skin and teat canal which may increase the chance of cow being falsely diagnosed as infected when the cow has no IMI (Frost et al., 1977; Mahmmod et al., 2013b), and (5) unexpected laboratory error during processing of the milk samples and/or during steps of the identification, differentiation and counting of S. aureus bacterial colonies. Although, we followed the standard rules of NMC (1999) for milk sampling and culturing procedures however, as in all biological data, diagnosing IMI is subject to error and we cannot guarantee that contamination during sample collection in the farm or sample processing in the laboratory would not happen. Edmondson (2011) identified $S$. aureus bacteria in three of the eight milk samples using PCR however; they were reported as Coagulase negative Staphylococci with BC, indicating the possibility of confusion between CNS and S. aureus. Although a frequent assumption is that the recovery of $S$. aureus from a single milk sample is evidence of IMI, false positive samples can occur with all pathogens including S. aureus (NMC, 1999).

The PCR and BC are two different kinds of tests with different principles for detection of bacteria. They were done on different milk samples; hence the differences between their estimates should be expected (Kelton and Godkin, 2000). It was reported that $11 \%$ of milk samples did not produce a match between PCR and BC (Edmondson, 2011). The difference can be influenced by other factors such as the differences in the used inoculum, where $350 \mu \mathrm{l}$ from the whole milking were taken for PCR, only $4 \times 10 \mu$ from quarter foremilk samples were taken for BC. The larger inoculum used for PCR in comparison to that of BC may be one of the reasons for a higher $\mathrm{Se}_{\mathrm{PCR}}$ as a larger inoculum generally increases the probability/chance of $S$. aureus detection. Furthermore, bacterial concentrations may have been different in the foremilk samples vs. the cow level samples taken subsequently in the same milking for PCR testing. In another study by the authors (unpublished data) the carryover effect between consequently milked cows in the same herds was estimated based on Ct value of PCR for S. agalactiae. Cows were positively correlated (1st autoregressive correlation) at PCR cut-off $\leq 37$ by $11 \%$, which may result in false positive PCR results.

This study was part of a larger project aiming to evaluate the diagnostic value of PCR technologies for udder health management in Danish dairy herds. One part of that broad project was to investigate the effect of presampling 
procedures on the PCR-positivity for mastitis pathogens. These procedures include teat cleaning, discarding the first milk streaks and $70 \%$ alcohol teat disinfection. These procedures are routinely done before sample collection for BC to reduce contamination and false positive due to teat canal and skin colonization (Haveri et al., 2008). On the other hand, such procedures are not routinely performed for PCR sampling. However, in the current study these procedures were applied before sampling for BC as well as PCR. It was found that applying pre-sampling procedures reduced the cow's odds of being PCR-positive for S. aureus by a factor of 0.75 (95\% CI: $0.58-0.97$ ) by reducing number of false positives (Mahmmod et al., 2013b).

To summarize, the difference between our obtained estimates (Se, Sp) for PCR and BC and estimates in other studies can be explained by many reasons such as the type of PCR (qualitative or quantitative or semi-quantitative), cut-off choice for Ct value of PCR, IMI definitions on BC (cutoff point for the number of colonies on $\mathrm{BC}$ ), frequency of sampling (single or duplicate) as reported by Erskine and Eberhart (1988), inoculum volume for BC (Walker et al., 2010), type of samples for BC (premilking sampling or postmilking sampling) as reported by Sears et al. (1991), handling of samples (fresh or freezing or centrifugation or non) as reported by (Godden et al., 2002), difference in the time of sampling for BC and PCR, different period of examination (dry off or lactating cows), difference in the sample size and study design, difference in the herds management and milking system (conventional milking systems or automatic milking systems), status of the cow at sampling and their history for $S$. aureus exposure.

Our estimate of $\mathrm{Se}_{\mathrm{CMT}}$ was lower than those estimates previously reported, 86\% (Sanford et al., 2006) and 66.7\%

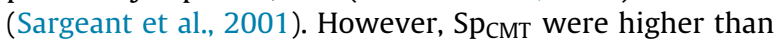
the estimate previously reported: 46\% (Sanford et al., 2006) and $54.8 \%$ (Sargeant et al., 2001). Se $\mathrm{C}_{\mathrm{CMT}}$ was higher than $\mathrm{Se}_{\mathrm{BC}}$ however; $\mathrm{Sp}_{\mathrm{BC}}$ was higher than $\mathrm{Sp}_{\mathrm{CMT}}$. These findings come in agreement with Sanford et al. (2006) for major mastitis pathogens (including $S$. aureus). The difference between $\mathrm{Se}_{\mathrm{CMT}}$ and $\mathrm{Se}_{\mathrm{BC}}$ may be argued by the non-specific reaction of CMT due to other mastitis pathogens or contamination. Environmental and physiological factors are proven to have a significant effect on the prevalence of positive quarters by CMT (Batra, 1980). Furthermore, the CMT uses a larger amount of milk sample (inoculum) for reaction. Hence, CMT should not be considered as a reliable specific test for detection of S. aureus IMI. Although, false positive results can be obtained from CMT, Sanford et al. (2006) concluded that selective dry-cow therapy might be done based on CMT results at dry-off for herds with majorpathogen IMI prevalence $<15 \%$. CMT was to have a useful role in dairy herd monitoring programmes for screening of the subclinical mastitis under field conditions (Sargeant et al., 2001; Kivaria et al., 2007).

\subsection{Model assumptions}

In the current study, the biological principles of PCR are different to those of BC and CMT, as PCR relies on the detection and quantifying the nuclear DNA of S. aureus (Koskinen et al., 2009). On the other hand, the biological principles of
$\mathrm{BC}$ and CMT are somehow related as both are based on the cellular contents of the milk. While $\mathrm{BC}$ relies on isolation of viable cells of $S$. aureus, CMT relies on detection of somatic and bacterial cells including $S$. aureus cells. Furthermore, CMT and BC were performed on the same quarter milk sample of the same cow at the same day. This relationship was confirmed based on the DIC value for the different models and combinations, where the model accounting for covariance between BC and CMT was preferred (DIC = 252.5). PCR was performed on composite milk samples directly, without the need for prior BC (Koskinen et al., 2009; Mahmmod et al., 2013a).

The assumption of differing prevalence between populations is central to LCA models (Toft et al., 2005). In the current study, the six different herds were considered as distinct populations with expected heterogenic true prevalence to $S$. aureus. This assumption was based on the differences seen in the monthly BTM PCR testing before starting the study in 28th March 2011. From Table 3, we infer that the posterior distribution of the true prevalence in the herds does differ. To ensure sufficient degrees of freedom, it is not necessary to have differences between all herds, thus the apparent lack of difference between $\mathrm{H} 1$ and $\mathrm{H} 2, \mathrm{H} 3$ and $\mathrm{H} 4$ and $\mathrm{H} 5$ and $\mathrm{H} 6$ is not important.

\subsection{Implications of misclassification}

Misclassification bias is a frustrating problem for mastitis diagnostics and may affect the test estimates under an evaluation due to false positives and false negatives results. The misclassification could be a misleading for the farmer and/or the veterinarians results in (1) building a wrong decision and subsequently, unnecessary costs for treatment, culling or even repeated sampling, or (2) missing the cows with true IMI and subsequently, spreading the infections within the herd. In their study, Friendship et al. (2010) concluded that false negatives and false positive results are associated with BC and PCR for identification of S. aureus IMI.

For PCR, the possibility of getting false positive and false negative results cannot be completely disregarded. The reasons for false positive PCR results may be caused by (1) regardless the bacterial cell status, PCR does not distinguish between viable and non-viable $S$. aureus bacteria, meaning that the non-viable bacteria are identified as positive, although it has no role in initiation/producing the infection, (2) there is no specific cut-off for describing the contamination for PCR (Koskinen et al., 2010; Spittel and Hoedemaker, 2012), in comparison to BC, where growth of three or more different colony species on the plate considered as contamination, (3) carryover effect (Friendship et al., 2010), and teat canal infections, (4) non-aseptically collected milk samples at DHI (Mahmmod et al., 2013b), and finally (5) cows that have successfully combatted $S$. aureus may still have a low $\mathrm{Ct}$ value even though the bacterial cells are killed. Hence, if the cow was tested by PCR, it will test positive although it was clinically recovered. Cows may cure $S$. aureus IMI spontaneously or following antibiotic therapy however, it might still $S$. aureus shedders (Kelton and Godkin, 2000). The Ct values may remain low after antibiotic treatments (Katholm, personal communication). 
Hence, identification of the truly infected cows and the discrimination of cows that are infected but are at various clinical stages are essential (Roesler et al., 2001). Therefore, the PCR-positivity for $S$. aureus does not by necessity mean that the cow is truly infected. This point may require further research work.

A negative result of $S$. aureus might be found in an infected cow when milk samples are collected during the period when the numbers of bacteria are at their lowest (or undetectable) levels (Anderson and Pritchard, 2012). A new $S$. aureus infection may have insufficient shedding to be detected by PCR or BC and insufficient tissue damage and/or induction to the cow immune system to be detected by CMT. Therefore, estimating the Se and Sp estimates without considering the dynamics of $S$. aureus infections, shedding pattern, response of cow's immune system, history and duration of infection, and new infections may not truly reflecting the status of the investigated cows. Our findings showed that misclassification due to false positives and false negatives results for PCR, BC and CMT may affect their estimates. However, this topic is beyond the scope of the current study objective and requires further investigation.

\section{Conclusion}

The use of LCA provided estimates of the test characteristics of two currently used diagnostic tests (BC, CMT) and a novel technique (real-time PCR) for diagnosing IMI with $S$. aureus under field conditions at routine milk recordings in Denmark. Test estimates of PCR (Se and Sp) were much higher than test estimates of $\mathrm{BC}$ and $\mathrm{CMT}$. $\mathrm{Se}_{\mathrm{CMT}}$ was higher than $\mathrm{Se}_{\mathrm{BC}}$ however; $\mathrm{Sp}_{B C}$ was higher than $\mathrm{Sp}_{\mathrm{C}}$. We conclude that PCR performs better than BC and CMT with respect to Se and Sp, suggesting its usefulness as a routine test for accurate diagnosis of $S$. aureus IMI from dairy cows at routine milk recordings.

\section{Acknowledgments}

This research work was funded by Faculty of Health and Medical Sciences, University of Copenhagen. The authors gratefully wish to acknowledge staff of Eurofins Steins Laboratory for providing us the lab space to conduct this research and for their technical and logistic support. They would like to thank Knowledge Centre for Agriculture, Cattle for funding of PCR testing and also, the technicians for their support in samples collection. Thanks to the Danish farmers for their help and making their cows available for our study.

\section{References}

Ahmadi, M., Rohani, S.M.R., Ayremlou, N., 2010. Detection of Staphylococcus aureus in milk by PCR. Comp. Clin. Pathol. 19, 91-94.

Anderson, K.L., Pritchard, D.E., 2012. An Update on Staphylococcus aureus Mastitis, Available at: http://www.cals.ncsu.edu/an_sci/ extension/dairy/newsletters/0403nlet.pdf (accessed 1.12.2012).

Barkema, H.W., Schukken, Y.H.,Zadoks, R.N., 2006. Invited review: the role of cow, pathogen, and treatment regimen in the therapeutic success of bovine Staphylococcus aureus mastitis. J. Dairy Sci. 89, 1877-1895.

Batra, T.R., 1980. The incidence of subclinical mastitis and related pathogens in two lines of dairy cattle. Can. J. Anim. Sci. 60, 743-748.
Bennedsgaard, T.W., Thamsborg, S.M., Aarestrup, F.M., Enevoldsen, C., Vaarst, M., Christoffersen, A.B., 2006. Resistance to penicillin of Staphylococcus aureus isolates from cows with high somatic cell counts in organic and conventional dairy herds in Denmark. Acta Vet. Scand. $48,24$.

Bexiga, R., Koskinen, M.T., Holopainen, J., Carneiro, C., Pereira, H., Ellis, K.A., Vilela, C.L., 2011. Diagnosis of intramammary infection in samples yielding negative results or minor pathogens in conventional bacterial culturing. J. Dairy Res. 78, 49-55.

Buelow, K., Nordlund, K., 1999. Factors affecting sensitivity and specificity of microbiological culture for Staphylococcus aureus. In: Proceeding of the 38th Annual Meeting of the National Mastitis Council, pp. 68-75.

Buelow, K.L., Thomas, C.B., Goodger, W.J., Nordlund, K.V., Collins, M.T. 1996. Effect of milk sample collection strategy on the sensitivity and specificity of bacteriologic culture and somatic cell count for detection of Staphylococcus aureus intramammary infection in dairy cattle. Prev. Vet. Med. 26, 1-8.

Cai, H.Y., Archambault, M., Gyles, C.L., Prescott, J.F., 2003. Molecular genetics methods in the veterinary clinical bacteriology laboratory: current usage and future applications. Anim. Health Res. Rev. 4, 73-93.

Cederlöf, S.E., Toft, N., Aalbaek, B., Klaas, I.C., 2012. Latent class analysis of the diagnostic characteristics of PCR and conventional bacteriological culture in diagnosing intramammary infections caused by Staphylococcus aureus in dairy cows at dry off. Acta Vet. Scand. 54, 65.

Dohoo, I.R., Meek, A.H., 1982. Somatic cell counts in bovine milk. Can. Vet. J. 23, 119-125.

Dohoo, I.R., Smith, J., Andersen, S., Kelton, D.F., Godden, S., Mastitis Research Workers' Conference, 2011. Diagnosing intramammary infections: evaluation of definitions based on a single milk sample. J. Dairy Sci. 94, 250-261

Edmondson, P.W., 2011. A practitioner's perspective of PCR testing and its comparison to conventional bacteriology. In: NMC 50th Annual Meeting, January 23-26, 2011, Arlington, Virginia, pp. 161-162.

Erskine, R.J., Eberhart, R.J., 1988. Comparison of duplicate and single quarter milk samples for the identification of intramammary infections. J. Dairy Sci. 71, 854-856.

Friendship, C., Kelton, D., Water, D.V., Slavic, D., Koskinen, M., 2010. Field evaluation of the Pathoproof mastitis PCR assay for the detection of Staphloccoccus aureus infected cows using DHI samples. In: NMC 49th Annual Meeting Proceedings, January 31-February 3, 2010, Albuquerque, New Mexico, pp. 226-227.

Frost, A.J., Wanasinghe, D.D., Woolcock, J.B., 1977. Some factors affecting selective adherence of microorganisms in the bovine mammary gland. Infect. Immun. 15, 245-253.

Gelman, A., Rubin, D.B., 1992. Inference from iterative simulation using multiple sequences. Stat. Sci. 7, 457-511.

Ghorbanpoor, M., Seyfiabad shapouri, M., Moatamedi, H., Jamshidian, M., Gooraninejad, S., 2007. Comparison of PCR and bacterial culture methods for diagnosis of dairy cattle's subclinical mastitis caused by Staphylococcus aureus. J. Vet. Res. 62, 87-91.

Godden, S.M., Jansen, J.T., Leslie, K.E., Smart, N.L., Kelton, D.F., 2002. The effect of sampling time and sample handling on the detection of Staphylococcus aureus in milk from quarters with subclinical mastitis. Can. Vet. J. 43, 38-42.

Halasa, T., Nielen, M., Huirne, R.B.M., Hogeveen, H., 2009. Stochastic bioeconomic model of bovine intramammary infection. Livest. Sci 124, 295-305.

Haveri, M., Hovinen, M., Roslof, A., Pyorala, S., 2008. Molecular types and genetic profiles of Staphylococcus aureus strains isolated from bovine intramammary infections and extramammary sites. J. Clin. Microbiol. 46, 3728-3735.

Hui, S.L., Walter, S.D., 1980. Estimating the error rates of diagnostic tests. Biometrics 36, 167-171.

Katholm, J., 2010. Streptococcus agalactiae in the Nordic countries. In: Proc. Veterinärkongressen, November 11-12, Uppsala, Sweden, pp. 77-80.

Katholm, J., Bennedsgaard, T.W., Koskinen, M.T., Rattenborg, E., 2012. Quality of bulk tank milk samples from Danish dairy herds based on real-time polymerase chain reaction identification of mastitis pathogens. J. Dairy Sci. 95, 5702-5708.

Kelton, D.F., Godkin, M.A., 2000. Mastitis culture programs for dairy herds. In: National Mastitis Council 41st Annual Meeting Proceedings, February 3-6, 2002, Orlando, Florida, pp. 54-62.

Kivaria, F.M., Noordhuizen, J.P., Nielen, M., 2007. Interpretation of California mastitis test scores using Staphylococcus aureus culture results for screening of subclinical mastitis in low yielding smallholder dairy cows in the Dar es Salaam region of Tanzania. Prev. Vet. Med. $78,274-285$ 
Koop, G., van Werven, T., Toft, N., Nielen, M., 2011. Estimating test characteristics of somatic cell count to detect Staphylococcus aureus-infected dairy goats using latent class analysis. J. Dairy Sci. 94, 2902-2911.

Koskinen, M., 2012. Validation of the PathoProof ${ }^{\mathrm{TM}}$ Mastitis PCR Assay for Bacterial Identification from Milk Recording Samples. http://www.icar.org/Documents/Porec_2009/B\%2012\%20May\% 20Afternoon/Koskinen.pdf (accessed 27.02.2013).

Koskinen, M.T., Holopainen, J., Pyorala, S., Bredbacka, P., Pitkala, A., Barkema, H.W., Bexiga, R., Roberson, J., Solverod, L., Piccinini, R., Kelton, D., Lehmusto, H., Niskala, S., Salmikivi, L., 2009. Analytical specificity and sensitivity of a real-time PCR assay for identification of bovine mastitis pathogens. J. Dairy Sci. 92, 952-959.

Koskinen, M.T., Holopainen, J., Salmikivi, L., Lehmusto, H., Niskala, S., Kurkela, J., 2008. Analytic detection limit of the PathoProof ${ }^{\mathrm{TM}}$ Mastitis PCR assay determined using two different experimental approaches. In: Mastitis Control-From Science to Practice. Proceedings of International Conference, September 30-October 2, 2008. Wageningen Academic Publishers, The Netherlands, pp. 183-189.

Koskinen, M.T., Wellenberg, G.J., Sampimon, O.C., Holopainen, J., Rothkamp, A., Salmikivi, L., van Haeringen, W.A., Lam, T.J.G.M., Pyörälä, S., 2010. Field comparison of real-time polymerase chain reaction and bacterial culture for identification of bovine mastitis bacteria. J. Dairy Sci. 93, 5707-5715.

Mahmmod, Y.S., Toft, N., Katholm, J., Grønbæk, C., Klaas, I.C., 2013a. Estimation of test characteristics of real-time PCR and bacterial culture for diagnosis of subclinical intramammary infections with Streptococcus agalactiae in Danish dairy cattle in 2012 using latent class analysis. Prev. Vet. Med. 109, 264-270.

Mahmmod, Y.S., Klaas, I.C., Nielsen, S.S., Katholm, J., Toft, N., 2013b. Effect of presampling procedures on real-time PCR used for diagnosis of intramammary infections with Staphylococcus aureus in dairy cows at routine milk recordings. J. Dairy Sci. 96, 2226-2233.

National Mastitis Council, 2004. Microbiological Procedures for the Diagnosis of Bovine Udder Infections and Determination of Milk Quality, 4th ed. NMC, Madison, WI.

National Mastitis Council, 1999. Laboratory Handbook on Bovine Mastitis. National Mastitis Council, Madison, WI

Paradis, M.E., Haine, D., Gillespie, B., Oliver, S.P., Messier, S., Comeau, J., Scholl, D.T., 2012. Bayesian estimation of the diagnostic accuracy of a multiplex real-time PCR assay and bacteriological culture for $4 \mathrm{com}$ mon bovine intramammary pathogens. J. Dairy Sci. 95, 6436-6448.

Reyher, K.K., Dohoo, I.R., Scholl, D.T., Keefe, G.P., 2012. Evaluation of minor pathogen intramammary infection, susceptibility parameters, and somatic cell counts on the development of new intramammary infections with major mastitis pathogens. J. Dairy Sci. 95, 3766-3780.

Roesler, U., Scholz, H., Hensel, A., 2001. Immunodiagnostic identification of dairy cows infected with Prototheca zopfii at various clinical stages and discrimination between infected and uninfected cows. J. Clin. Microbiol. 39, 539-543.

Sanford, C.J., Keefe, G.P., Sanchez, J., Dingwell, R.T., Barkema, H.W., Leslie, K.E., Dohoo, I.R., 2006. Test characteristics from latent-class models of the california mastitis test. Prev. Vet. Med. 77, 96-108.
Sargeant, J.M., Leslie, K.E., Shirley, J.E., Pulkrabek, B.J., Lim, G.H., 2001. Sensitivity and specificity of somatic cell count and California mastitis test for identifying intramammary infection in early lactation. J. Dairy Sci. 84, 2018-2024.

Schalm, O.W., Noorlander, D.O., 1957. Experiments and observations leading to development of the California Mastitis Test. J. Am. Vet. Med. Assoc. 130, 199-204.

Schukken, Y.H., Wilson, D.J., Welcome, F., Garrison-Tikofsky, L., González, R.N., 2003. Monitoring udder health and milk quality using somatic cell counts. Vet. Res. 34, 579-596.

Sears, P.M., Smith, B.S., English, P.B., Herer, P.S., Gonzalez, R.N., 1990. Shedding pattern of Staphylococcus aureus from bovine intramammary infections. J. Dairy Sci. 73, 2785-2789.

Sears, P.W., Wilson, D.J., Gonzalez, R.N., 1991. Microbiological results from milk samples obtained premilking and postmilking for the diagnosis of bovine intramammary infections. J. Dairy Sci. 74, 4183-4188.

Sol, J., Sampimon, O.C., Hartman, E., Barkema, H.W., 2002. Effect of preculture freezing and incubation on bacteriological isolation from subclinical mastitis samples. Vet. Microbiol. 85, 241-249.

Sørensen, L.P., Mark, T., Sørensen, M.K., Ostergaard, S., 2010. Economic values and expected effect of selection index for pathogen-specific mastitis under Danish conditions. J. Dairy Sci. 93, 358-369.

Spiegelhalter, D.J., Best, N.G., Carlin, B.P., van der Linde, A., 2002. Bayesian measures of model complexity and fit (with discussion). J. Roy. Stat. Soc. B 64, 583-640.

Spittel, S., Hoedemaker, M., 2012. Mastitis diagnosis in dairy cows using PathoProof ${ }^{\mathrm{TM}}$ real-time polymerase chain reaction assay in comparison with conventional bacterial culture in a Northern German field study. Berl. Munch. Tierarztl. Wochenschr. 125, 494-502.

Taponen, S., Salmikivi, L., Simojoki, H., Koskinen, M.T., Pyörälä, S., 2009. Real-time polymerase chain reaction-based identification of bacteria in milk samples from bovine clinical mastitis with no growth in conventional culturing. J. Dairy Sci. 92, 2610-2617.

Thomas, A., O’Hara, B., Ligges, U., Sturtz, S., 2006. Making BUGS open. R News 6 (1), 12L 17.

Toft, N., Akerstedt, J., Tharaldsen, J., Hopp, P., 2007. Evaluation of the three serological tests for diagnosis of Maedi-Visna virus infection using latent class analysis. Vet. Microbiol. 120, 77-86.

Toft, N., Jørgensen, E., Højsgaard, S., 2005. Diagnosing diagnostic tests: evaluating the assumptions underlying the estimation of sensitivity and specificity in the absence of a gold standard. Prev. Vet. Med. 68, 19-33.

Villanueva, M.R., Tyler,J.W., Thurmond, M.C., 1991. Recovery of Streptococcus agalactiae and Staphylococcus aureus from Fresh and Frozen Bovine Milk. J. Am. Vet. Med. Assoc. 198, 1398-1400.

Walker, J.B., Rajala-Schultz, P.J., DeGraves, F.J., 2010. The effect of inoculum volume on the microbiologic detection of naturally occurring Staphylococcus aureus intramammary infections. J. Vet. Diagn. Invest. 22, 720-724

Walker, J.B., Rajala-Schultz, P.J., Walker, W.L., Mathews, J.L., Gebreyes, W.A., DeGraves, F.J., 2011. Variation in daily shedding patterns of Staphylococcus aureus in naturally occurring intramammary infections. J. Vet. Diagn. Invest. 23, 1114-1122. 